Васюков Евгений Александрович

аспирант кафедры мировой экономики Московского государственного университета им. М.В. Ломоносова

\section{ВАЛЮТНАЯ ПОЛИТИКА КИТАЯ В КОНТЕКСТЕ СОВРЕМЕННЫХ РЕАЛИЙ ВАЛЮТНОГО РЫНКА}

\section{Аннотация:}

Китайская экономика является крупнейшей в мире при этом в стране до сих пор жестко контролируется значение валютного курса. Посредством существенного расхода валютных резервов прави тельству удается поддерживать курс на целевом уровне. Однако постоянные ожидания девальвации юаня негативно сказываются на планах инвесторов относительно китайской экономики, что приводит к значительному оттоку капитала. В работе рассмотрена возможность перехода к плавающему режиму, который обеспечит достаточную гибкость, а также предотвратит чрезмерную регулируемость и "бегство» капитала. Столкнувшись с завышенными ожиданиями обесценивания юаня, нынешняя политика стабилизации обменного курса может не оказать должного эффекта, а также сократить благосостояние государства изза дорогостоящих операций на открытом рынке.

Ключевые слова:

валютная политика Китая, валютный курс, валютный режим, движение капитала.
Vasyukov Evgeny Aleksandrovich

PhD student

World Economy Subdepartment Lomonosov Moscow State University

\section{CURRENCY POLICY OF CHINA IN THE CONTEXT OF MODERN REALITIES OF THE FOREIGN EXCHANGE MARKET}

Summary

The Chinese economy is the largest in the world while it still strictly controls the exchange rate value. Through a significant expenditure of foreign exchange reserves, the government manages to maintain the rate at the target level. Nevertheless, the constant expectations of the renminbi devaluation have a negative impact on the investors' plans for the Chinese economy, which leads to a significant capital outflow. The paper reviews the possibility of transition to a floating regime that will provide sufficient flexibility as well as prevent excessive controllability and flight of capital. Faced with high expectations of the renminbi depreciation, the current policy of stabilizing the exchange rate may be inefficient and reduce the country's welfare due to expensive transactions on the open market.

Keywords: currency policy of China, exchange rate, exchange rate regime, capital flows.

Валютные курсы важны для многих предприятий, которые покупают или продают на международном уровне. Даже простые фрирмы, скорее всего, имеют цепочку поставок, которая включает в себя некоторые импортные продукты. Китайская экономика - крупнейшая в мире, в ней сосредоточены производство и сбыт множества компаний, при этом в стране до сих пор действует жесткий контроль над значением валютного курса. Недавнее заявление о том, что правительство будет жестче влиять на обменные курсы, ставит вопрос о том, куда именно власти хотят направить курс [1].

В Китае с 1994 по 2005 г. действовал фриксированный режим, когда юань был привязан к валюте США на уровне 8,28 за доллар. В июле 2005 г. Пекин объявил, что будет переоценивать юань, и привязал его к корзине валют. При таком подходе Народный банк Китая (ЦБ) следил за колебаниями валюты, но тренд определял сам рынок.

В августе 2015 г. ЦБ объявил, что продолжит реформу режима обменного курса юаня с акцентом на большем влиянии спроса и предложения на формирование значения курса. Подобное заявление застало рынок врасплох; юань немедленно «упал» и достиг нижнего предела диапазона флуктуации в течение следующих 2 дней. В январе 2016 г. был принят новый механизм формирования, основанный на цене закрытия и теоретической стоимости обменного курса, которая сохранит индекс корзины валют без изменений. Главный смысл этой методики заключается в том, чтобы принимать во внимание как рыночные спрос и предложение, так и стабильность валютной корзины [2].

Из страха перед свободным падением юаня Банк Китая вмешался в ситуацию, чтобы проконтролировать масштабы снижения курса. В результате рыночная реформа обменного курса была внезапно прервана. Хотя вмешательство в конечном счете стабилизировало обменный курс юаня, риск девальвации все еще ощущается. Отсюда вытекает проблема того, как избежать негативного воздействия девальвационных ожиданий на китайскую экономику и реализовать рыночную реформу режима валютного курса. Также возникает вопрос: готова ли китайская экономика к плавающему режиму валюты [3]. 
В основные меры валютной политики Китая входят два инструмента: операции на открытом рынке и валютный контроль. Ко второму могут быть отнесены ограничения на покупку валюты фризическими лицами (годовой объем покупки не должен превышать 50 тыс. долл.), а также ужесточение наказания за нелегальную перевозку валюты через границу. Самым существенным является требование почти для всех предприятий обязательного обмена иностранной валюты, находящейся в их распоряжении [4].

Однако вмешательство имеет издержки. Усилия ЦБ по управлению обменным курсом и прекращению оттока капитала уменьшают его возможности корректировки внутренних затрат по займам, а также достижения компромисса в трилемме международных фринансов. Кроме того, это негативно сказывается на валютных резервах страны, которые приблизились к мировому максимуму в 4 трлн долл. в июне 2014 г., а теперь готовы «упасть» ниже 3 трлн долл. - на самый низкий уровень с начала 2011 г. (рисунок 1) [5].

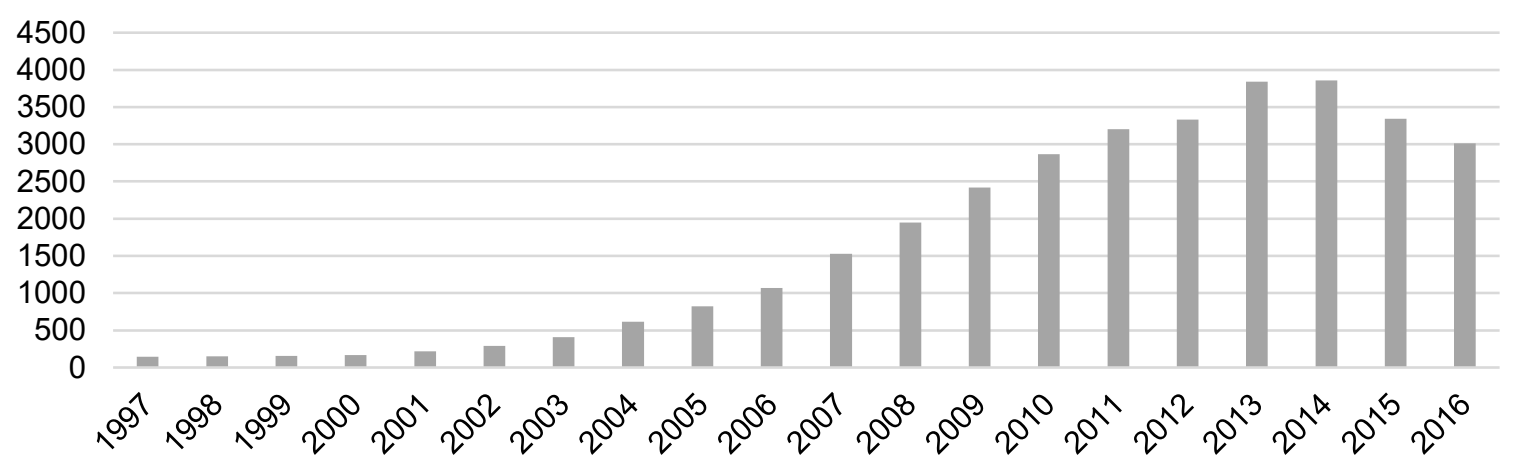

Рисунок 1 - Объем валютных резервов в Китае в 1997-2016 гг., млрд долл. США [6]

Существующий подход дает возможность политикам управлять темпами обесценения юаня, предотвращая резкие колебания рынка, способные дестабилизировать финансовую систему. Экономическая стабильность особенно важна в период выборов на ключевые посты в государстве, которые пройдут в 2017 г. Поэтому легко понять, почему системе обменного курса, позволяющей осуществлять усиленный контроль, отдается предпочтение [7].

Исходя из динамики объема операций ЦБ, можно предположить, что после долгих лет занижения курса национальной валюты на данном этапе усилия направлены в сторону его завышения. В то время как юань обесценился по отношению к доллару более чем на 11 \% в номинальном значении (с 6,24 до 6,95 юаня за доллар за последние 2 года [8]), реальный эффективный курс возрос на $15 \%$ и остается на 7 \% выше уровня середины 2014 г. (рисунок 2). Подобное поведение валютного курса юаня отражает не силу экономики Китая, а усилия китайских политиков по предотвращению «падения» по сравнению с долларом США.

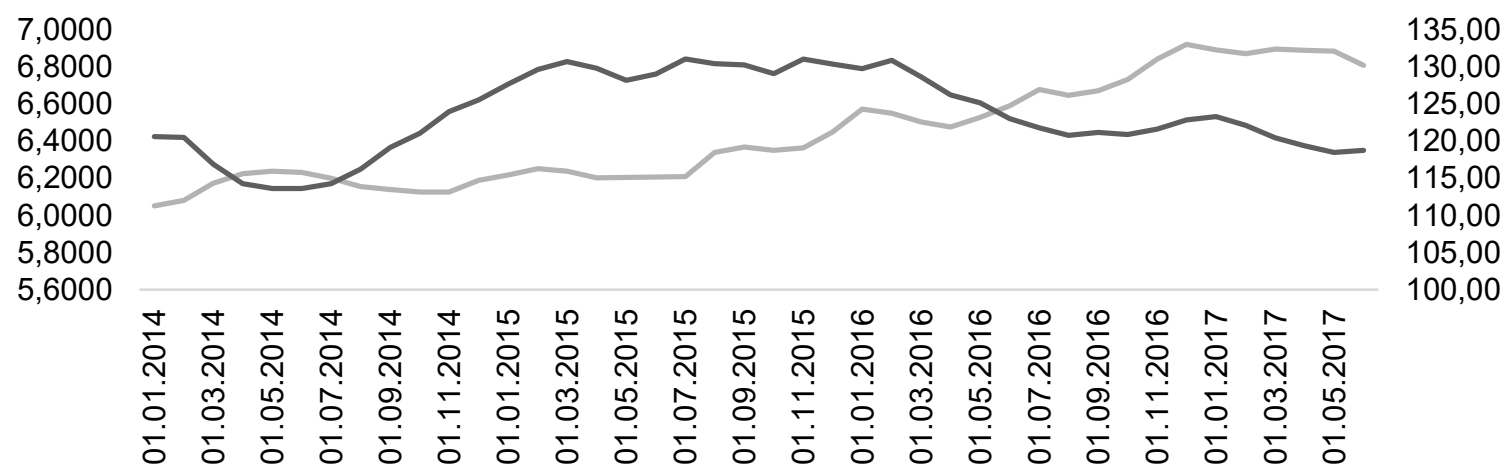

— Номинальный курс юаня к доллару —— Реальный эффективный валютный курс юаня

\section{Рисунок 2 - Номинальный курс юаня к доллару США и реальный эффективный обменный курс юаня}

Средства управления, скорее всего, лишь тормозят неизбежное. Несмотря на то что китайские резервные запасы остаются крупнейшими в мире, если экономика не проявит способность расширяться, не полагаясь на новый всплеск кредита, сомнения в фринансовой системе и устойчивости развития, вероятно, будут усиливаться. 
Завышенное значение говорит о том, что при отсутствии контроля со стороны государства курс юаня был бы ниже нынешнего. Возникает вопрос: насколько оправданны усилия ЦБ и не эффективнее ли отпустить его в «свободное плавание». В краткосрочной перспективе это, вероятно, спровоцировало бы «падение» относительно доллара США. Учитывая сильную склонность Китая к рыночному вмешательству, в том числе его неоднозначную роль в 2015-2016 гг., иностранные вкладчики могут начать выводить ресурсы, опасаясь действий встревоженных политиков и возврата к старой тактике [9]. Конечно, ограничения, введенные после 2015 г., смогли частично замедлить данную тенденцию, но эти меры можно назвать исключительно временными (рисунок 3).

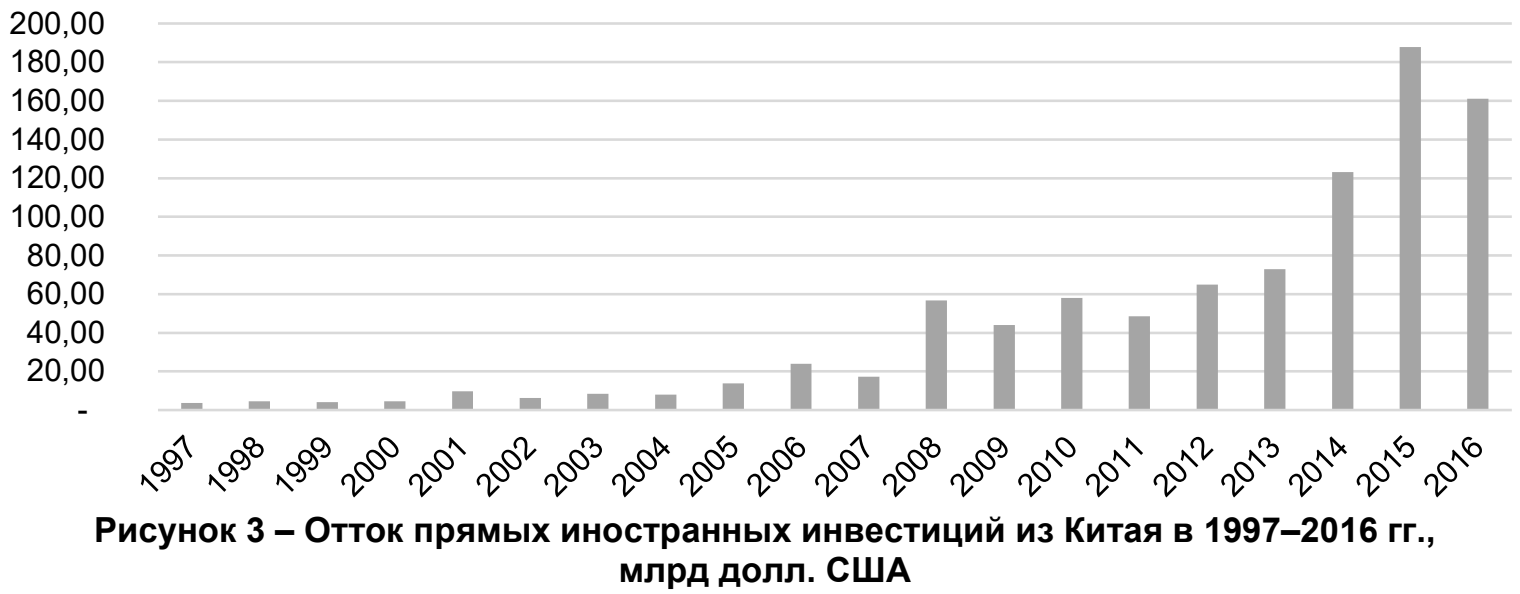

В долгосрочной перспективе регулирование движения капитала не решит проблему, вместо этого использование сбережений страны станет менее эффективным. Быстрый переход к рыночному обменному курсу позволил бы государству сохранить валютные резервы, восстановить контроль над внутренней денежно-кредитной политикой и избежать критики о манипулировании валютой со стороны США. К тому же валютные резервы в Китае являются сбережениями нации, им можно было бы найти лучшее применение, нежели пустые траты на интервенцию на валютном рынке [10].

Однако возникают следующие опасения. Если в этом году Федеральная резервная система США увеличит расходы по займам, свободный курс юаня начнет снижаться, что подтолкнет капитал к оттоку. При этом, учитывая все еще значительный объем резервов, профицит торгового баланса и низкую инфляцию, резкого и существенного «падения» валюты ожидать не приходится [11].

Независимо от того, какая политика обменного курса может быть реализована и какой режим валютного курса может быть принят, Китаю по-прежнему необходимо поддерживать контроль над капиталом, чтобы уменьшить давление на юань и избежать фринансового кризиса, вызванного огромным оттоком капитала и другими фринансовыми фракторами. Серия событий 2015 г. продемонстрировала, что в стране еще не созданы условия для либерализации счета движения капитала, а также для полного конвертирования юаня [12].

Как и в любом государстве с фиксированным обменным курсом, ЦБ Китая активно вмешивается в рыночную ситуацию для достижения целевых валютных показателей. В течение последних 2 лет Народный банк Китая делал это, чтобы замедлить снижение курса своей валюты, а не способствовать ее обесцениванию по отношению к доллару. Это привело к переоцененности юаня и негативным ожиданиям инвесторов относительно его динамики.

Рыночная реформа валютного режима имеет решающее значение для трансформации экономической системы Китая и является одним из ключевых условий для эффективной реализации макроэкономической политики. Независимо от направленности давления на валюту без гибкого обменного курса, который сможет быстро реагировать спрос и предложение, ресурсы государства будут истощаться, потери национального благосостояния будут увеличиваться вместе с оттоком капитала (в 2016 г. 650 млрд долл.) [13].

Тем не менее, пока перспективы укрепления доллара сохраняются, стимулы для ограничения контроля за движением капитала будут оставаться высокими, ведь на карту поставлена макроэкономическая стабильность. Завышенные ожидания обесценивания юаня приводят к реализации политики стабилизации обменного курса, не только дорогостоящей, но и неустойчивой из-за быстрого истощения валютных резервов. Китай должен следовать программе постепенного отказа от фриксации, при этом обращая особое внимание на регулирование движения капитала во избежание деструктивных последствий для экономики. 


\section{Ссылки и примечания:}

1. Morrison W.M., Labonte M. China's Currency: Economic Issues and Options for US Trade Policy [Электронный ресурс] : CRS Report for Congress // Congressional Research Service. 2008. Vol. 14. URL: https://fas.org/sgp/crs/row/RL32165.pdf (дата обращения: 07.08.2017).

2. Eichengreen B. China's exchange rate trap [Электронный pecypc] // The Guardian. 2016. Febr., 9. URL: https://www.theguardian.com/business/2016/feb/09/china-economy-currency-exchange-rate-renminbi (дата обращения: 07.08.2017).

3. Yao K. China forex reserves fall $\$ 512.66$ billion in 2015, biggest drop on record [Электронный ресурс] // Reuters. 2016. Jan., 7. URL: http://www.reuters.com/article/us-china-economy-forex-reserves-idUSKBNOUL13W20160107 (дата обращения: 07.08.2017).

4. Annual Report on Exchange Arrangements and Exchange Restrictions [Электронный ресурс] // International Monetary Fund. 2016. URL: https://www.imf.org/en/Publications/Annual-Report-on-Exchange-Arrangements-and-ExchangeRestrictions/Issues/2017/01/25/Annual-Report-on-Exchange-Arrangements-and-Exchange-Restrictions-2016-43741 (дата обращения: 07.08.2017).

5. Bradsher K. How China Lost \$1 Trillion [Электронный ресурс] // The New York Times. 2017. Febr., 7. URL: https://www.nytimes.com/interactive/2017/02/07/business/china-bank-foreign-reserves.html (дата обращения: 07.08.2017)

6. Все рисунки составлены на основе данных The World Bank data catalog (www.data.worldbank.org).

7. Lee J. A Free-Floating Yuan Is Looking a Bit More Likely [Электронный ресурc]. URL: https://www.bloomberg.com/news/articles/2017-01-11/pimco-says-china-s-next-market-shock-may-be-a-freely-traded-yuan (дата обращения: 07.08.2017).

8. На основе данных The World Bank data catalog.

9. Yu Y., Zhang B. Renminbi Exchange Rate: Peg to A Wide Band Currency Basket // China \& World Economy. 2017. No. 1.

10. Swanson A., Paletta D. Trump says he will not label China currency manipulator, reversing campaign promise [Электронный pecypc] // The Washington Post. 2017. April, 12. URL: https:/www.washingtonpost.com/news/wonk/wp/2017/04/12/trumpsays-he-will-not-label-china-currency-manipulator-reversing-campaign-promise (дата обращения: 07.08.2017).

11. Conerly B. China Exchange Rate Forecast: More Stable Than Headlines Suggest [Электронный ресурс]. URL: https://www.forbes.com/sites/billconerly/2017/05/30/china-exchange-rate-forecast-more-stable-than-headlines-suggest/\#716723106498 (дата обращения: 07.08.2017).

12. Prasad A. A Middle Ground [Электронный ресурc]. URL: http://prasad.dyson.cornell.edu/doc/F\&DRMBArticle.Mar17.pdf (дата обращения: 07.08.2017).

13. Fang C., Wong S.-L. China FX reserves stay above \$3 trillion after small March rise [Электронный ресурс] // Reuters. 2017. April, 12. URL: http://in.reuters.com/article/china-economy-forex-reserves-idINKBN1791AQ (дата обращения: 07.08.2017).

\section{References:}

'Annual Report on Exchange Arrangements and Exchange Restrictions' 2016, International Monetary Fund, viewed 07 August 2017, <https://www.imf.org/en/Publications/Annual-Report-on-Exchange-Arrangements-and-Exchange-Restrictions/lssues/2017/01/25/Annual-Report-on-Exchange-Arrangements-and-Exchange-Restrictions-2016-43741>

Bradsher, K 2017, 'How China Lost \$1 Trillion', The New York Times, February, 7, viewed 07 August 2017, <https://www.nytimes.com/interactive/2017/02/07/business/china-bank-foreign-reserves.html>.

Conerly, B 2017, China Exchange Rate Forecast: More Stable Than Headlines Suggest, viewed 07 August 2017, $<$ https://www.forbes.com/sites/billconerly/2017/05/30/china-exchange-rate-forecast-more-stable-than-headlines-suggest/\#716723106498>

Eichengreen, B 2016, 'China's exchange rate trap', The Guardian, February, 9, viewed 07 August 2017, <https://www.theguardian.com/business/2016/feb/09/china-economy-currency-exchange-rate-renminbi>

Fang, C \& Wong, S-L 2017, 'China FX reserves stay above $\$ 3$ trillion after small March rise', Reuters, April, 12, viewed 07 August 2017, <http://in.reuters.com/article/china-economy-forex-reserves-idINKBN1791AQ>.

Lee, J 2017, A Free-Floating Yuan Is Looking a Bit More Likely, viewed 07 August 2017, <https://www.bloomberg.com/news/articles/2017-01-11/pimco-says-china-s-next-market-shock-may-be-a-freely-traded-yuan>.

Morrison, WM \& Labonte, M 2008, 'China's Currency: Economic Issues and Options for US Trade Policy: CRS Report for Congress', Congressional Research Service, vol. 14, viewed 07 August 2017, <https://fas.org/sgp/crs/row/RL32165.pdf>.

Prasad, A 2017, A Middle Ground, viewed 07 August 2017, <http://prasad.dyson.cornell.edu/doc/F\&DRMBArticle.Mar17.pdf>

Swanson, A \& Paletta, D 2017, 'Trump says he will not label China currency manipulator, reversing campaign promise', The Washington Post, April, 12, viewed 07 August 2017, <https://www.washingtonpost.com/news/wonk/wp/2017/04/12/trump-sayshe-will-not-label-china-currency-manipulator-reversing-campaign-promise>.

Yao, K 2016, 'China forex reserves fall $\$ 512.66$ billion in 2015, biggest drop on record', Reuters, January, 7, viewed 07 August 2017, <http://www.reuters.com/article/us-china-economy-forex-reserves-idUSKBNOUL13W20160107>

Yu, Y \& Zhang, B 2017, 'Renminbi Exchange Rate: Peg to A Wide Band Currency Basket', China \& World Economy, no. 1. 